\title{
A Rare Cause of Vertigo- Case Report and Review of Literature
}

\author{
Sabharisan Paramasivam*, Karthikeyan Ramasamy, Arun Alexander and Sunil Kumar Saxena \\ Department of ENT, Jawaharlal Institute of Postgraduate Medical Education and Research, India
}

Submission: October 19, 2020; Published: December 01, 2020

*Corresponding author: Sabharisan Paramasivam, Junior resident, Department of ENT, Jawaharlal Institute of Postgraduate Medical Education and Research, India

Abstract

Presence of air within the labyrinth constitutes the term Pneumo-labyrinth. Pneumo-labyrinth may be associated with perilymph fistula. Most commonly trauma involving the otic capsule is associated with pneumolabyrinth. Depending on the location of the air bubble within the inner ear pneumolabyrinth can be subdivided into pneumocochlea and pneumovestibule, in which air is present in the cochlea and vestibule respectively [1]. In this case report we discuss
a. regarding a case of vertigo
b. management of pneumo-labyrinth and
c. review of literature.

Keywords: Pneumo labyrinth; Vertigo; Pneumocochlea; Pneumovestibule; Auditory canal; Trauma; Otorhinolaryngology; Hearing loss; Fascia graft; Tissue seal; Footplate; Labyrinth; Hypothesis; Basilar membrane; Dysfunction; Stria vascularis; Scala tympani

\section{Case Report}

50 years old male patient presented to Outpatient Department with history of giddiness and ringing sensation in the ear for two months. He also complained of reduced hearing in the right year. On further probing of history, he gave history of trauma to the right ear two and a half months ago while doing field work, where while loading goods a stick had accidentally injured his right ear (stick entered into his external auditory canal). Following the trauma, he had one episode of ear bleed immediately.

In examination, on otoscopy examination of the right ear tympanic membrane was intact and mobile with signs of healed perforation. In the left ear he had a small central perforation involving the inferior quadrant. Bilateral facial nerve was intact and had no cerebellar signs. Rest of the otorhinolaryngology examination was normal. Pure tone audiogram showed $>90 \mathrm{~dB}$ hearing loss and 48dB hearing loss (moderately mixed hearing loss) in right and left ear respectively (Table 1). High Resolution Computed Tomography (HRCT) of the temporal bones showed presence of air pocket within the membranous labyrinth.

Anesthetic clearance was obtained and exploratory tympanotomy was planned. Intra operatively stapes dislocation with fracture of stapes supra-structure were present. Dislocated stapes was removed, defect in the oval window was identified and was sealed with temporalis fascia graft and tissue seal. The stapes was repositioned back into the middle ear over the graft and was packed around with gel foam. Post-operative period was uneventful. Labyrinthine sedatives were given in the postoperative period. Wound sutures were removed on post-operative day 10. Symptomatic relief of giddiness was present post operatively on follow up. Post-operatively he did not give history of improvement in hearing (Figures 1-3).

Table 1: Tuning fork test results of the patient.

\begin{tabular}{|c|c|c|}
\hline Tuning Fork Test & Right & Left \\
\hline Rinne's test & & - \\
\hline $256 \mathrm{~Hz}$ & - & - \\
\hline $512 \mathrm{~Hz}$ & - & - \\
\hline $1024 \mathrm{~Hz}$ & - & \\
\hline $\begin{array}{c}\text { Weber's test (512Hz) } \\
\text { Absolute bone conduction } \\
\text { (512Hz) }\end{array}$ & Reduced & same as examiner \\
\hline
\end{tabular}




\section{Global Journal of Otolaryngology}

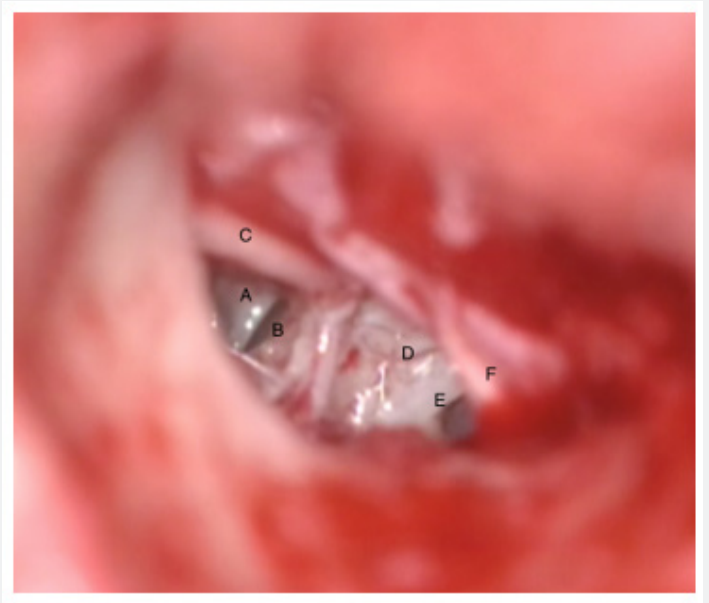

Figure 1: Microscopic image of the middle ear during surgery. A- Dislocated Stapes; B- Oval window fistula; C- Long process of incus; DPromontory; E- Round window; F- Anteriorly reposited tympano-meatal flap.

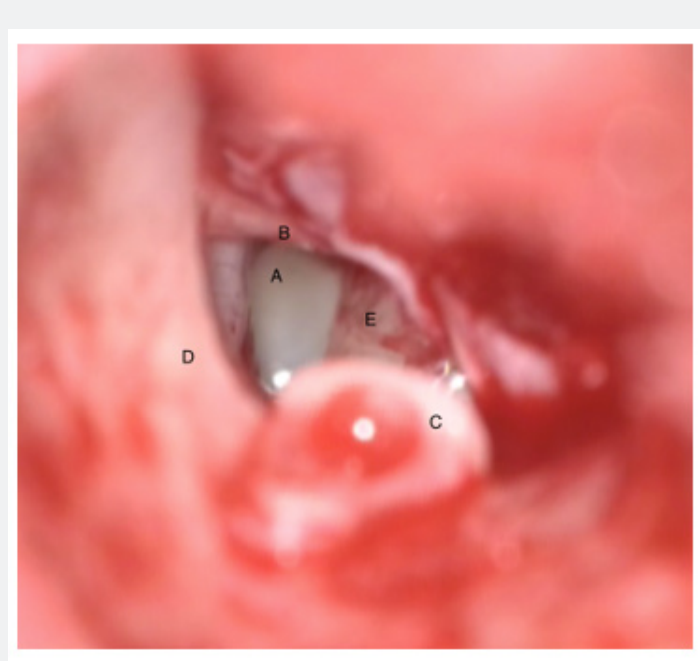

Figure 2: Microscopic image of middle ear during surgery. A: Oval window fistula; B- Long process of incus; C- Stapes removed from the middle ear; D: Posterior canal wall; E- Promontory.

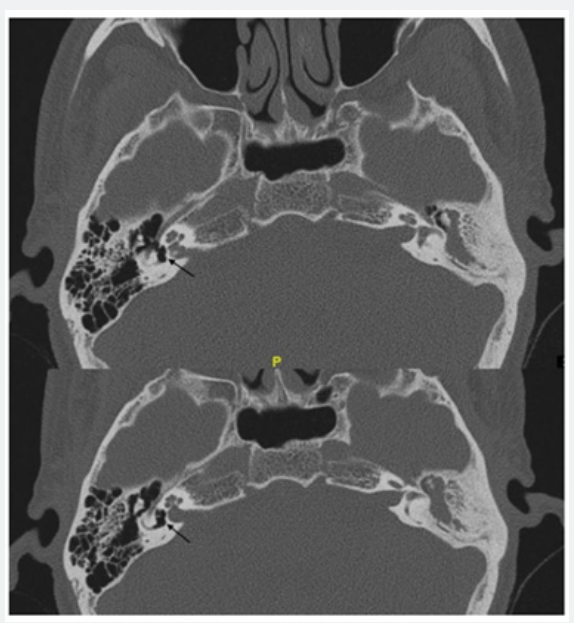

Figure 3: High Resolution Computed Tomography images of temporal bone (axial view). Black arrow indicates air bubble within the labyrinth. 


\section{Discussion}

Temporal bone trauma could be otic capsule involving or otic capsule sparing. Pneumolabyrinth could be seen in both these conditions, but more common among otic capsule violating temporal bone fracture patients. The incidence of occurrence of pneumolabyrinth is seldom in comparison to other sequelae of temporal bone trauma. In a series by Choi et al the incidence of pneumolabyrinth was $8 \%$ among the trauma cases with temporal bone fracture while in another series by Choi et al it was $1.5 \%$ $[2,3]$. The various causes other than temporal bone fracture causing pneumolabyrinth are rupture of round window due to an impulsive force, perilymphatic fistula, displacement of stapes prosthesis into vestibule, congenital malformations, fracture or dislocation or subluxation of stapes and cochleostomy with cochlear implant within [4-10]. Stapes footplate luxation out of the oval window or into the vestibule is rare [6-9]. The two main reasons being

i. stapes is firmly attached to the oval window due to annular ligament and

ii. the anatomical location of stapes deep within the middle ear [6].

The most probable mechanism of injury in the present case might be that the foreign object entered the middle ear after perforating the tympanic membrane and got hinged near to the stapes. Upon withdrawal of the foreign body it might have caused dislocation of the stapes footplate leading to patient's current symptoms. Patients with pneumolabyrinth can also present with delayed onset of symptoms $[11,12]$.

Diagnosing a patient of pneumolabyrinth is important for appropriate management. Mafee et al. were the first to describe pneumolabyrinth in computed tomography and suggested the presence of pneumolabyrinth as a feature of stapes footplate fracture [13]. Thereafter High-Resolution Computed Tomography (HRCT) became an essential entity in diagnosing pneumolabyrinth. Presence of air within the labyrinth appears as black areas in HRCT. These air pockets might move with movement of head while attaining HRCT and chance of dislocation of the air bubble is also possible in cases with disrupted membranous labyrinth [14]. The probability of positive HRCT finding increases when imaging study is acquired immediately following trauma. Though over time on serial imaging these air bubbles might dissipate $[3,14]$. Choi et al. advocates obtaining early HRCT imaging to predict the audio-vestibular outcome [3].

The exact cause for sensorineural hearing loss among these subsets of patients might be due to the direct injury of membranous labyrinth and might be due to the presence of air bubble within the labyrinth. One hypothesis is that these air bubbles cause disruption of the travelling wave along the basilar membrane [4]. Kobayashi et al in their study concluded that hearing loss is due to interference in the generation of cochlear microphonics and compound action potential rather than dysfunction of the stria vascularis. Further on comparison between the findings of presence of air in scala vetibuli and scala tympani, even with a very small volume of air $(3 \mu \mathrm{L})$ there was hearing loss in scala vestibule. Hearing did not return to the baseline on removal of air from scala vestibule in some cases [15].

The treatment options available for management are either observation or surgical exploration. Surgical exploration can be considered in cases with progressive sensorineural or fluctuating hearing loss and in patients having persistent vertigo [4]. Exploratory tympanotomy serves useful for diagnosing as well as for surgical management. The major lacuna in managing these cases are the lack of sructured protocol due to very few numbers of cases. The vestibular symptoms usually alleviate post operatively as per Tsubota et al. The hearing improvement as per their study is dependent on three predictive factors:
a. existence of stapes lesion
b. bone conduction hearing level at the onset of the disease
c. time interval until surgery [9]

Yet another predictive factor as per Hidaka et al. is the location of air bubble. Better hearing outcome can be expected in pneumocochlea whereas outcomes are poorer in cases of pneumovestibule or in combination of both [16]. Various surgical methods have been described example using fascia to repair the involved window along-with muscle obliteration or using tragal perichondrium [4]. When taken up for surgery, the patient should be made aware that even after surgery there may/may not be any hearing improvement.

\section{Conclusion}

Even-though pneumo-labyrinth is a rare entity that we encounter clinically, a general prospective on its clinical features and findings are must to diagnose these less frequent cases for adequate management. We should also keep in mind that treatment of dizziness among these patients is often successful while the same cannot be for treatment of hearing loss.

\section{References}

1. Gross M, Ben Yaakov A, Goldfarb A, Eliashar R (2003) Pneumolabyrinth: an unusual finding in a temporal bone fracture. Int J Pediatr Otorhinolaryngol 67(5): 553-555.

2. Choi JW, Lyu A R, Ryu KA, Kim D, Park Y H (2016) Detection of pneumolabyrinth after temporal bone trauma using computed tomography. Acta Otolaryngol (Stockh) 136(7): 682-686.

3. Choi H, Lee H J, Lee J, Kim D, Hong S, Park B, et al. (2015) The Rates and Clinical Characteristics of Pneumolabyrinth in Temporal Bone Fracture. Otol Neurotol 36(6): 1048-1053.

4. Scheid SC, Feehery JM, Willcox TO, Lowry LD (2001) Pneumolabyrinth: A Late Complication of Stapes Surgery. Ear Nose Throat J 80(10): 750753.

5. Lee JS, Kwon SY, Kim JH, Kim H J (2015) Bilateral Sequential Pneumolabyrinth Resulting from Nose Blowing. J Audiol Otol 19(3): 182-185. 
6. Sarac S, Cengel S, Sennaroglu L (2006) Pneumolabyrinth following traumatic luxation of the stapes into the vestibule. Int J Pediatr Otorhinolaryngol 70(1): 159-161.

7. Nishiike S, Hyo Y, Fukushima H (2008) Stapediovestibular dislocation with pneumolabyrinth. J Laryngol Otol 122(4): 419-421.

8. Choe KS, Arigo J, Zeifer B (2002) Stapediovestibular Dislocation. Otol Neurotol 23(1):102-103.

9. Tsubota M, Shojaku H, Watanabe Y (2009) Prognosis of inner ear function in pneumolabyrinth: case report and literature review. Am J Otolaryngol 30(6): 423-436.

10. Karataş E, Toplu Y, Gündüz E, Demir İ (2018) Severe Vertigo After Cochlear Implantation: Acute Pneumolabyrinth. Balk Med J 35(5): 408-409.

11. Nakashima T, Matsuda K, Okuda T, Tono T, Takaki M, et al. (2015) Late Pneumolabyrinth May Be Induced by Old Penetrating Injury: Possibility of Undiagnosed Posttraumatic Perilymphatic Fistula. Case Rep Otolaryngol.
12. Nurre J, Miller G, Ball J (1988) Pneumolabyrinth as a late sequela of temporal bone fracture. Am J Otol 9(6): 489-493.

13. Mafee M, Valvassori G, Kumar A, Yannias D, Marcus R (1984) Pneumolabyrinth: A New Radiologic Sign for Fracture of the Stapes Footplate. Am J Otol 5(5): 374-375.

14. de Negreiros J, Sampaio ALL, Sesana WE, Oliveira CA (2008) Imaging Case Study of the Month Traumatic Pneumolabyrinth. Ann Otol Rhinol Laryngol 117(9): 708-710.

15. Kobayashi T, Sakurada T, Ohyama K, Takasaka T (1993) Inner Ear Injury Caused by Air Intrusion to the Scala Vestibuli of the Cochlea. Acta Otolaryngol (Stockh) 113(6):725-730.

16. Hidaka H, Miyazaki M, Kawase T, Kobayashi T (2012) Traumatic Pneumolabyrinth: Air Location and Hearing Outcome. Otol Neurotol 33(2): 123-131.

\section{Your next submission with Juniper Publishers} will reach you the below assets

- Quality Editorial service

- Swift Peer Review

- Reprints availability

- E-prints Service

- Manuscript Podcast for convenient understanding

- Global attainment for your research

- Manuscript accessibility in different formats ( Pdf, E-pub, Full Text, Audio)

- Unceasing customer service

Track the below URL for one-step submission https://juniperpublishers.com/online-submission.php 